\title{
LETTERS
}

\section{Concern about quality of palliative care}

In their article in CMAJ, Downar and colleagues draw conclusions that could have a far-reaching impact on the public's perception of medical assistance in dying (MAiD), based on potentially misleading data. ${ }^{1}$ According to an article in the Globe and Mail, "The authors of the new Ontario research say its findings - which are based on reviews of every assisted-dying case in the province over 2 years - counter fears that the procedure would become a final refuge for patients too poor and vulnerable to access highquality health services, including palliative care. Instead, the opposite has proved true: It is the affluent, not the marginalized, who most often avail themselves of the assisted-dying law that Canada enacted nearly four years ago." 2

The data for this study were based on self-reporting of the MAiD provider, and not by the patient. Evidence by selfreporting is often biased toward compliance with regulations. Case in point: a review of anonymous questionnaires from Belgium reveals that self-reporting led to only 1 in 2 cases being actually reported to authorities as euthanasia. Those not formally reported were correlated with decreased adherence to guidelines and lacking in palliative care involvement. $^{3}$

Given we are on the brink of MAiD expansion in Canada without a foreseeable death clause, a study prematurely declaring no concerns for the vulnerable is alarming and reckless.

It is also important to consider whether being affluent precludes vulnerability. Is financial abuse of older adults a nonissue in Canada? ${ }^{4}$ Could poor clinical acumen in helping patients adjust to loss of power or function and high rates of depression still be hidden in these figures?

\section{Ramona Coelho MDCM}

Family physician, London, Ont.

Cite as: CMAJ 2020 May 19;192:E556. doi: $10.1503 / \mathrm{cmaj} .74916$

\section{References}

1. Downar J, Fowler RA, Halko R, et al. Early experience with medical assistance in dying in Ontario, Canada: a cohort study. CMAJ 2020;192: E173-E181

2. Grant K. Wealthier patients more likely to use medical assistance in dying, data show. Globe and Mail [Toronto]. Available: www.theglobeandmail.com/ canada/article-wealthier-patients-more-likely-to -use-medical-assistance-in-dying/ (accessed 2020 Feb. 11).

3. Smets T, Bilsen J, Cohen J, et al. Reporting of euthanasia in medical practice in Flanders, Belgium: cross sectional analysis of reported and unreported cases. BMJ 2010;341:c5174.

4. Elder abuse: it's time to face the reality. Ottawa: Employment and Social Development Canada; 2009, modified 2016 Oct. 24. Available: www. canada.ca/en/employment-social-development/ campaigns/elder-abuse/reality.html\#a (accessed 2020 Feb. 14).

Competing interests: None declared. 